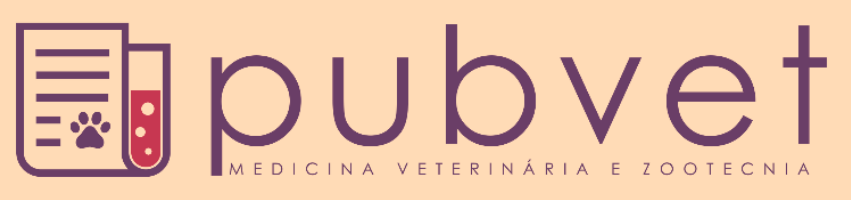

https://doi.org/10.31533/pubvet.v13n5a322.1-4

\title{
Sarna demodécica em cão adulto: Relato de caso
}

\author{
Rosimeri Spegiorin ${ }^{1}$, Tatiana Palma Durlo ${ }^{2 *}$ \\ ${ }^{I}$ Graduanda do $5^{o}$ período de Medicina Veterinária na instituição Unochapecó, Chapecó SC, Brasil. \\ ${ }^{2}$ Graduanda do $9{ }^{\circ}$ período de Medicina Veterinária na instituição Unochapecó. Chapecó SC, Brasil. E-mail:t.durlo@unochapeco.edu.br \\ *Autor para correspondência, E-mail: spegiorin@unochapeco.edu.br
}

Resumo. A sarna demodécica canina é causada mais comumente pelo ácaro Demodex canis e acomete cães de todas as idades, prevalecendo nos cães jovens. É de grande importância veterinária uma vez que a patologia frequentemente leva à furunculose e infecção bacteriana secundária, assim seu diagnóstico, tratamento e acompanhamento são fundamentais no controle da doença. Como é passível de ser confundida com outras doenças de pele, a anamnese e o exame clínico se tornam imprescindíveis no atendimento veterinário. Com o objetivo de analisar um caso desta dermatopatia em cão, buscou-se uma caracterização do animal e do estágio da doença, além da busca por embasamento teórico sobre a doença. Com base na caracterização da mesma, foi realizado o tratamento tópico com shampoos medicamentosos, e sistêmico com antibióticos e anti-acaricidas, além do acompanhamento periódico do paciente.

Palavras chave: Demodex canis, demodiciose, dermatopatia

\section{Demodex sp in adult dogs: Case report}

\begin{abstract}
The canine demodicosis is caused by Demodex canis and is present in the most part of their life, mainly in puppies. It is of great veterinary importance since the pathology often leads to furunculosis and secondary bacterial infection, so its diagnosis, treatment and follow-up are fundamental in the control of the disease. As it is likely to be confused with other skin diseases, anamnesis and clinical examination become essential in veterinary pratice. The objective is analyze a case of this dermatopathy in dogs, the characterization of the animal and the stage of the disease, as well as the search for theoretical basis on the disease. Based on its characterization, treatment with medicated shampoo was performed; and systemic treatment with antibiotics and anti-acarids, besides the periodic follow up of the patient.
\end{abstract}

Keywords: Demodex canis, demodicosis, skin disease

\section{Sarna demodécica en perro adulto: Reporte de un caso}

Resumen. La sarna demodécica canina es causada más comúnmente por el ácaro Demodex canis y afecta perros de todas las edades, prevaleciendo en los perros jóvenes. Es de gran importancia veterinaria ya que la patología a menudo conduce a la forunculosis e infección bacteriana secundaria, por lo que su diagnóstico, tratamiento y seguimiento son fundamentales en el control de la enfermedad. Como es sujeto a ser confundida con otras enfermedades de la piel, la anamnesis y el examen clínico se vuelven imprescindibles en la atención veterinaria. Con el objetivo de analizar un caso de esta dermatopatía en perro, se buscó una caracterización del animal y del estadio de la enfermedad, además de la búsqueda por basamento teórico sobre la enfermedad. Con base en la caracterización de esta, se realizó el tratamiento tópico con champús medicamentosos, y sistémico con antibióticos y anti acaricidas, además del acompañamiento periódico del paciente.

Palabras clave: Demodex canis, demodiciosa, dermatopatía 


\section{Introdução}

O tecido comum recobre os animais desempenhando várias funções, dentre as principais: barreira contra agentes mecânicos, físicos ou biológicos; termorregulação; recepção sensorial de calor, frio, dor; defesa imunológica (König \& Liebich, 2016). Por ser o órgão de maior contato direto com o ambiente e seus fatores, a pele é acometida por várias patologias, sejam causadas por fungos, bactérias, ou infecções parasitárias, como a sarna. Nos cães, as sarnas mais manifestadas podem ser do tipo sarcóptica ou demodécica. A primeira causada por ácaros da família Sarcoptidae (gêneros Sarcoptes e Notoedres); já a segunda por ácaros da família Demodecidae, gênero Demodex (Scott et al., 1996). Estudos comprovam que a incidência de sarna demodécica em cães é significativa, principalmente, em cães jovens e determinadas raças, bem como pode levar à morte de cães adultos, ao que se deve a importância de relatar este trabalho (Pinho et al., 2015). Além disso, esta dermatose pode desencadear ou favorecer o aparecimento de outras doenças concomitantes, o que torna importante seu conhecimento, diagnóstico e estudo (Medleau et al., 2003; Sampaio \& Rivitti, 2000).

O presente trabalho teve o objetivo de relatar um caso de sarna demodécica observado em cão adulto atendido em clínica veterinária na cidade de Chapecó - Santa Catarina. Para tal, se delineou o estudo com a caracterização do animal e análise clínica física e geral realizadas; descrição do tratamento; e identificação métodos de acompanhamento.

\section{Material e métodos}

O caso objeto deste estudo ocorreu em uma clínica veterinária na cidade de Chapecó - SC, na data de dezembro de 2017, sendo o acompanhamento aqui descrito realizado até agosto de 2018. Chegou a clínica veterinária uma canino fêmea da raça shih tzu com aproximadamente seis anos de idade, não castrada, peso corporal de 3,9 kg, apresentando escore corporal abaixo do normal (Figura 1A), alopecia generalizada na cauda e localizada nas extremidades dos membros torácicos e pélvicos (Figura 1B). Fez-se a avaliação clínica do animal que apresentou parâmetros fisiológicos normais. A fim de um diagnóstico mais acurado, realizou-se tosa geral no animal que permitiu identificadar todas as lesões generalizadas. A paciente apresentava escala oito de prurido (animal dava preferência a se coçar a se alimentar) e recém tinha saído da lactação.

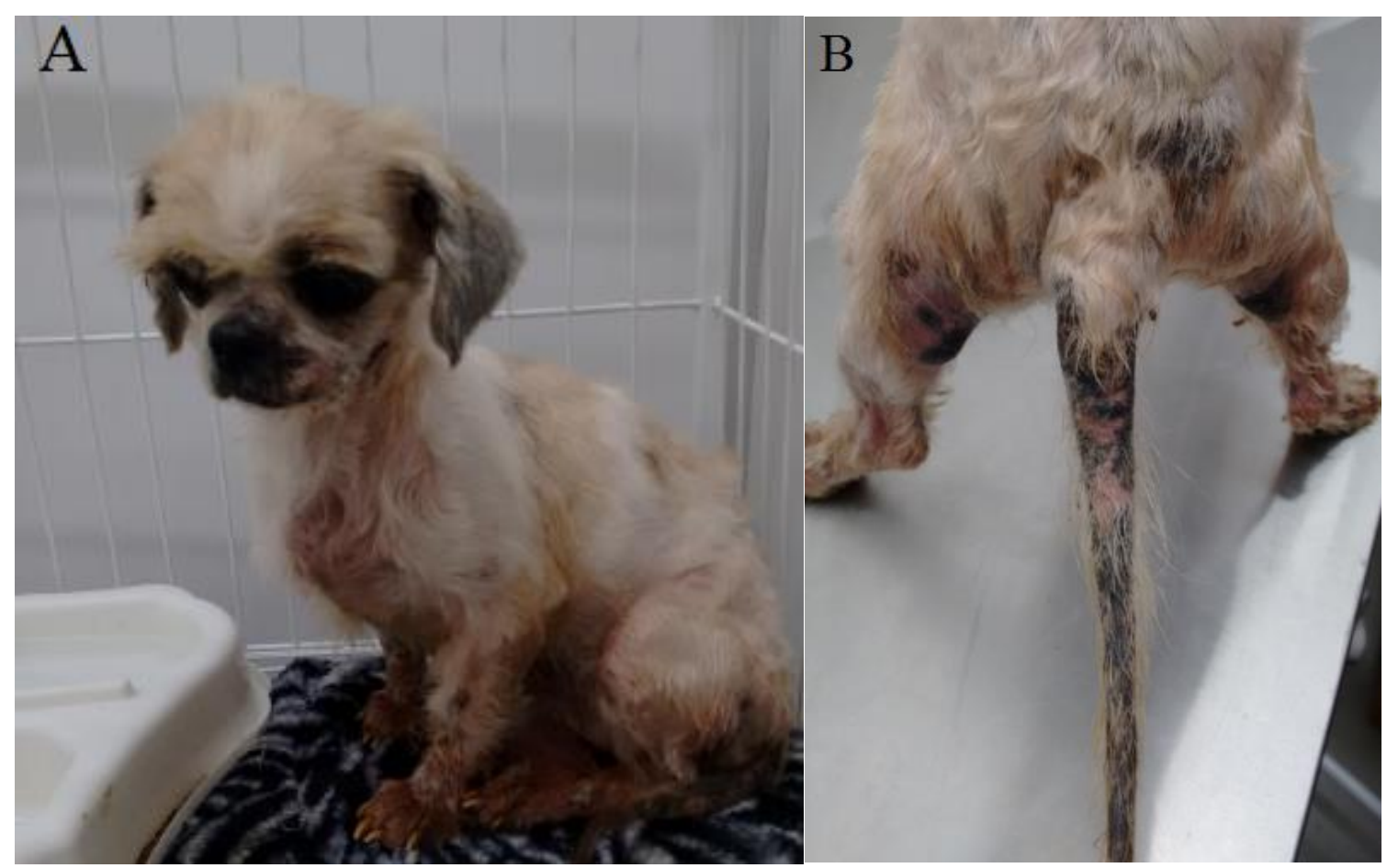

Figura 1. Canina fêmea da raça shih tzu com escore corporal abaixo do normal (A), alopecia generalizada na cauda e localizada nas extremidades do membro pélvico $(\mathbf{B})$. 
Em seguida foram coletados materiais para a realização dos exames hematológicos e dermatológicos. O material (sangue) para o exame hematológico (hemograma completo) foi encaminhado para um laboratório veterinário da localidade. $\mathrm{O}$ exame dermatológico foi realizado na própria clínica onde $\mathrm{o}$ médico veterinário responsável, com auxílio de um bisturi e lâmina, coletou material (raspado cutâneo) das diferentes regiões do animal, principalmente das áreas alopécicas. Este material foi disposto sobre lâminas contendo uma ou duas gotas de soro fisiológico e levadas imediatamente ao microscópio óptico para avaliação.

\section{Resultados e discussão}

A sarna demodécica canina é causada mais comumente pelo ácaro Demodex canis e acomete cães de todas as idades, especialmente os mais jovens. O agente é um parasita comensal do animal, desenvolvendo a doença quando o sistema imune é prejudicado e proporcional aumento de ácaros no organismo, com a proliferação deste nos folículos pilosos ou mesmo no extrato córneo da pele e glândulas sebáceas da pele (Patel \& Forsythe, 2011).

Esta dermatopatia tem origem na multiplicação descontrolada do ácaro Demodex sp., constitui uma doença parasitária em que o agente habita o hospedeiro, ocupando o folículo piloso e glândulas sebáceas na derme dos cães e é transmitida aos filhotes pelo contato direto da mãe nos primeiros dias de vida, na fase de amamentação. A presença do ácaro não causa a doença necessariamente, ela é desencadeada, principalmente, pela imunossupressão do animal quando a multiplicação do ácaro promove lesões nos folículos e glândulas sebáceas na pele (Balda et al., 2004; Patel \& Forsythe, 2011; Pinho et al., 2015). A sarna demodécica pode ser classificada como demodiciose localizada ou demodiciose generalizada e irá depender das manifestações clínicas, podendo ser de caráter juvenil ou adulto.

A literatura aponta a sarna demodécica generalizada, podendo ser de caráter juvenil ou adulto, como uma das mais severas dermatopatia em cães (Nagelstein, 2010; Zanon et al., 2008). Em Santa Catarina, há registros de que 52,8\% dos cães atendidos em clínicas têm ocorrência de ectoparasitas, a nível brasileiro os casos de Demodex canis alcançam $40 \%$ a 48,2\% dos casos de sarna canina (Matos et al., 2012; Zur et al., 2002). Como o aparecimento de lesões por demodiciose em cães está relacionado à imunodepressão e esta última tem diversas causas, que podem ser de uma má nutrição, parto, ou até lesões por outras ecto ou endoparasitoses, um diagnóstico preciso e precoce pode trazer melhores respostas ao tratamento (Nagelstein, 2010). As dermatopatias são relevantes na clínica veterinária e, em razão disso, faz-se necessária realização de exames complementares a fim de diagnosticar corretamente o agente etiológico e um adequado tratamento. Para tal, foi realizado na paciente exames laboratoriais: hemograma e raspado cutâneo. No hemograma foi encontrado leucocitose, indicando infecção bacteriana; e eosinofilia indicando processo alérgico. Na leitura das lâminas do microscópio foram encontradas grande número de formas imaturas do ácaro do gênero Demodex sp. Conforme aponta literatura, achados exacerbados de formas imaturas do ácaro comparadas a formas maduras constitui eficaz diagnóstico da demodiciose (Patel \& Forsythe, 2011; Scott et al., 1996). Com base nos achados laboratoriais foram prescritos e realizados banhos semanais com cetoconazol e clorexidine $2 \%$, associado a antibiótico a base de cefalexina $75 \mathrm{mg}$ via oral duas vezes ao dia (BID) durante dez dias; e 01 comprimido de sarolaner a cada trinta dias durante três meses.

É fundamental o acompanhamento do tratamento após uso de acaricida (quando este é utilizado), que pode ser feito com raspados cutâneos seriados em comparativo de exames parasitológicos anteriores. Este acompanhamento é necessário porque a cura clínica antecede a eliminação dos ácaros. Ainda, um aspecto da patologia é a hereditariedade, sendo assim, recomendada a castração dos cães adultos com sarna demodécica generalizada desenvolvida (Patel \& Forsythe, 2011).

Na paciente foi realizado o acompanhamento semanal por três meses, com coletas de raspado cutâneo que demonstraram eficiência gradativa do tratamento. Neste período foi identificada sua significativa melhora do estado corporal e fisiológico: as lesões dermatológicas apresentaram redução progressiva e por consequência aumento das áreas de repilação. Após a completa recuperação das lesões dermatológicas, realizou-se o procedimento cirúrgico de castração (OSH - ovário salpico histerectomia) para evitar novamente a imunossupressão do animal. Evento este que é desencadeado, geralmente, no período reprodutivo do animal devido às variações hormonais. 
Por fim, o tutor foi orientado a monitorar o animal, realizando retornos periódicos ao médico veterinário para avaliação.

\section{Conclusões}

A sarna demodécica tem ocorrência em todo território brasileiro e, por se tratar de um parasita oportunista, não deve ser tratada de forma isolada no animal. O sistema imune comprometido é porta de entrada para o ácaro se proliferar e lesionar tecidos, o que torna importante a avaliação e tratamento sistêmicos adequados.

É de grande importância veterinária, uma vez que a patologia frequentemente leva à furunculose e infecção bacteriana secundária, assim seu diagnóstico, tratamento e acompanhamento são fundamentais no controle da doença que afeta grande número de cães, sem detrimento de idade ou região geográfica. Como é passível de ser confundida com outras doenças de pele, a anamnese e o exame clínico se tornam imprescindíveis no atendimento veterinário.

A divulgação de formas de tratamentos nas diversas situações, como neste caso, é fator sinérgico para redução de cães acometidos por demodiciose sem tratamento. Ainda, o compartilhamento de casos, protocolos de tratamento levam conhecimento à população em geral, fazendo-a tomar medidas profiláticas, evitando e/ou reduzindo os índices da patologia em estudo.

\section{Referências bibliográficas}

Balda, A. C., Larsson, C. E., Otsuka, M. \& Gambale, W. (2004). Estudo retrospectivo de casuística das dermatofitoses em cães e gatos atendidos no Serviço de Dermatologia da Faculdade de Medicina Veterinária e Zootecnia da Universidade de São Paulo. Acta Scientiae Veterinariae, 32(2):133-140.

König, H. E. \& Liebich, H. G. (2016). Anatomia dos animais domésticos: texto e atlas colorido. Porto Alegre, Rio Grande do Sul, Brasil: Editora Artmed.

Matos, C. B., Madrid, I. M., Santin, R., Azambuja, R. H., Schuch, I., Meireles, M. C. A. \& Cleff, M. B. (2012). Multifactorial dermatitis in a dog. Arquivo Brasileiro de Medicina Veterinária e Zootecnia, 64(6): 1478-1482.

Medleau, L., Hnilica, K. A. \& Fagliari, G. S. (2003). Dermatologia de pequenos animais: atlas colorido e guia terapêutico. São Paulo: Roca.

Nagelstein, A. F. (2010). Patogenia da dermatite atópica em cães. Centro Universitário da Grande Dourado, Dourados, Mato Grosso do Sul.

Patel, A. \& Forsythe, P. J. (2011). Dermatologia em pequenos animais. Rio de Janeiro: Elsevier Brasil.

Pinho, R. M., Monzón, M. F. \& Simões, J. (2015). Dermatologia veterinária em animais de companhia.

Sampaio, S. A. P. \& Rivitti, E. A. (2000). Dermatologia (1155p.). São Paulo: Artes Médicas.

Scott, D. W., Muller, G. H. \& Kirk, R. W. (1996). Dermatologia dos pequenos animais (Vol. 1). Rio de Janeiro: Interlivros.

Zanon, J. P., Gomes, L. A., Cury, G. M. M., Teles, T. C. \& Bicalho, A. P. C. V. (2008). Dermatite atópica canina. Semina: Ciências Agrárias, 29(4):905-920.

Zur, G., Ihrke, P. J., White, S. D. \& Kass, P. H. (2002). Canine atopic dermatitis: a retrospective study of 266 cases examined at the University of California, Davis, 1992-1998. Part I. Clinical features and allergy testing results. Veterinary Dermatology, 13(2):89-102.

Recebido: 12 de março, 2019.

Aprovado: 30 de abril, 2019.

Publicado: 21 de maio, 2019.

Licenciamento: Este artigo é publicado na modalidade Acesso Aberto sob a licença Creative Commons Atribuição 4.0 (CCBY 4.0), a qual permite uso irrestrito, distribuição, reprodução em qualquer meio, desde que o autor e a fonte sejam devidamente creditados. 